\title{
XXXV. Efficiency of production of X rays from a Coolidge tube
}

\author{
Sir Ernest Rutherford F.R.S. \& Prof. J. Barnes Ph.D.
}

To cite this article: Sir Ernest Rutherford F.R.S. \& Prof. J. Barnes Ph.D. (1915) XXXV. Efficiency of production of $X$ rays from a Coolidge tube , Philosophical Magazine Series 6, 30:177, 361-367, DOI: $10.1080 / 14786440908635406$

To link to this article: http://dx.doi.org/10.1080/14786440908635406

曲 Published online: 08 Apr 2009.

Submit your article to this journal $₫$

山 Article views: 10

Q View related articles $\square$

Citing articles: 1 View citing articles 5 
XXXV. Efficiency of Production of X Rays jrom a Coolidge The. By Sir Ernest RUthenfond, F.R.S., and Prof. J. Barisis, Ph.Ll.*

$\mathbf{J}^{\mathrm{N}}$ the preceding paper we have given an account of 1 experiments which have been made to determine the maximum frequency of the $\mathrm{X}$ radiation excited in a Coolidge tube for different constant voltages supplied by a Wimshurst machine. It was thought desirable to extend the experiments to determine the efficiency of the production of $\mathrm{X}$ rays in the Coolidge tube for comparatively high voltages.

The question of the efficiency of the production of $\mathrm{X}$ rays, $i$.e. the ratio of the energy of the generated $X$ rays to that of the exciting cathole rays, has been the subject of several investigations. Wient determined the energy of the $\mathrm{X}$ rays generated in a platiuum anticathode for a potential difference of 58,700 volts, by measuring the heating effect of the radiation. Similar experiments have been made by Angerer $\ddagger$ and Carter $\S$. The latter observed that the efficiency increased with the exciting voltage. In general, it was found that the efficiency was of the order of $1 / 1000$.

Recently the question has been attacked under more definite conditions by R.T. Beatty $\|$. Cathode rays of definite velocity sorted out by a magnetic field fell on a radiator. The generated $X$ rays passed out through a very thin window, and were then completely absorbed in a cylinder $150 \mathrm{~cm}$. long filled with the vapour of methyl iodide. The total ionization of the rays was thus measured, and the corresponding energy deduced from general data. When characteristic radiation was not excited, the energy of the $X$ rays for an equal number of exciting electrons was found to be proportional to the fourth power of the velocity of the cathode rays. Kaye - had previously observed that the energy of $\mathrm{X}$ rays under constant condition of excitation was approximately proportional to the atomic weight $A$ of the radiator. Beatty finally concluded that the efficiency of production of $\mathrm{X}$ rays by matter in general was given by the formula

$$
\frac{\mathrm{X} \text {-ray energy }}{\text { cathode-ray energy }}=2.54 \times 10^{-4} \mathrm{~A} \beta^{2} \text {, }
$$

* Communicated by the Authors.

+ Wien, Ann.d. Phys. xviii. p. 991 (1905).

$\ddagger$ Angerer, Ann. d. Phys. xxi. p. 87 (1906).

§ Carter, Ann. d. Phys. xxi. p. 955 (1906).

II Beatty, Proc. Roy. Soc. A. lxxxix. p. 314 (1913).

I Kaye, Phil. Trans. Roy. Soc. A. cciv. p. 123 (1908); Proc. Roy. Soc. A. lxxxi. p. 337 (1908). 
where $\beta$ is the velocity of the cathode as a fraction of the velocity of light. From the curves given by Beatty, it would appear that the maximum speed of the cathode rays employed by him corresponded to 23,000 volts.

In the experiments with the Coolidge trbe we have examined the efficiency of production of the radiation escaping from the bulb for voltages $48,000,64,000$, and 96,000 volts. The rays were excited by a Wimshurst machine, and the current through the bulb measured by a galvanometer. The general arrangements for controlling and calibrating the voltage were the same as those described in the accompanying paper. For the high voltages employed, the radiation is too penetrating for complete absorption in a reasonable length of air or other gas. In order to overcome this difficulty, we have measured the ionization due to a definite length of a beam of $X$ rays in air, and deduced the absorption in air indirectly by determining the absorption curve of the radiation in water. It is known that the absorption of $\mathrm{X}$ rays by complex molecules is additive. The absorption of the radiation by water is mainly due to the oxygen atoms, whose atomic weight differs only slightly from that of the average atomic weight of air. For the relatively penetrating rays employed, we can assume with very little error that the absorption of the $X$ rays by water is very nearly equal to that of a column of air of the same thickness compressed to the same density. The absorption by $1 \mathrm{~cm}$. thickness of water is thus equivalent to that by $8 \cdot 2$ metres of air at laboratory temperature.

The ionization due to the $\mathrm{X}$ rays was measured in air without the $X$ rays impinging on the electrodes in order to avoid the introduction of surface effects due to scattering or

Fig. 1.

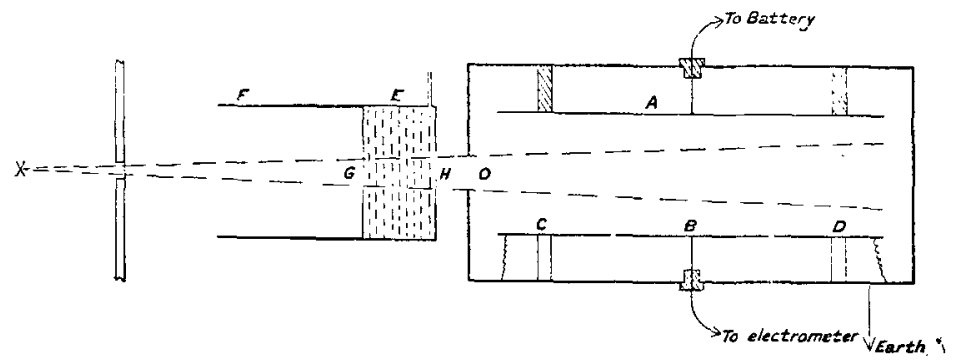

excitation of characteristic radiations. The general arrangement of the apparatus is shown in fig. 1 . The ionization vessel consisted of a rectangular box $(20 \times 12 \times 12 \mathrm{~cm}$.) lined 
with aluminium plate. The ionization was measured between the aluminium plate $\mathrm{A}$ and the central plate $\mathrm{B}$. The former was connected to a 1000 -volt battery and the latter to the electrometer. Two additional plates C, D connected with earth extended on both sides of the plate B. The cone of rays entering the ionization vessel was fixed by the circular opening $0,2 \mathrm{~cm}$. in diameter, in a lead plate, the size of opening being adjusted so that no radiation fell on the electrodes. The disturbing effect due to the $\mathrm{X}$ rays impinging on the aluminium end of the box was small, and could be neglected. In order to determine the absorption curve for water, a vessel was constructed consisting of two closely fitting brass tubes $\mathbf{E}$ and $F$. Openings, $G, H$, cut in the ends of these tubes, were covered with a thin sheet of mica. The length of the column of water in the path of the rays could be simply adjusted, and care was taken that the radiation entering the ionization vessel did not strike the brass ends of the vessel. The maximum length of the column of water in the experiment was $5 \mathrm{~cm}$. It is seen from fig. 2 that this is sufficient to reduce the intensity of the radiation to a small fraction of its initial value.

Fig. 2.

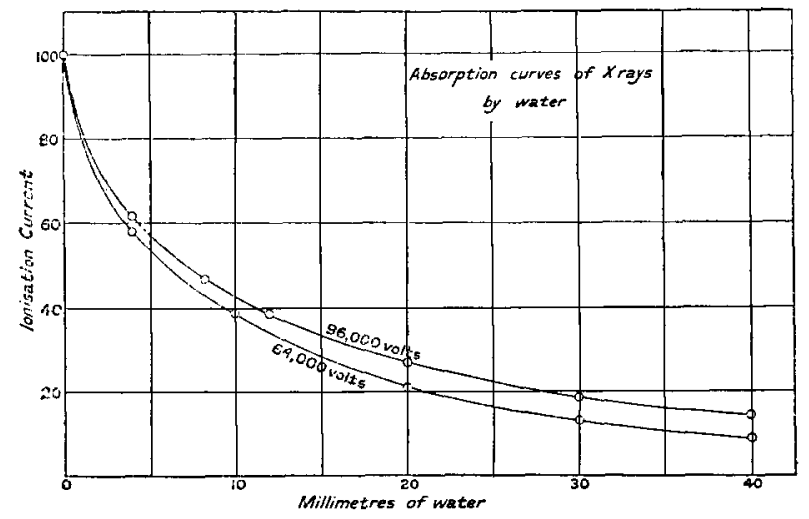

In order to determine the absorption of the end part of the radiation by water, the vessel EF was removed, and a sufficient thickness of aluminium introduced in the path of the rays to reduce the ionization to an equal degree. The water column was again introduced, and the experiments continued up to a thickness of $15 \mathrm{~cm}$. of water.

The capacity of the circuit and of the condensers in parallel was carefully determined. Changes in the intensity of the 
radiation were controlled by means of the "standardizing vessel " described in a previous paper, and also by the current passing through the Coolidge tube. This current was determined by the method described in a previous paper. The deflexion of the galvanometer in the circuit was observed; the current through the tungsten spiral broken, and the voltage kept at the same value by varying the speed of the machine and by means of adjustable point discharge. The deflexion observed under the latter conditions was due to the current through the xylol resistances and voltage galvanometer in parallel with the Coolidge tube, and to electrical losses in the leads or over the surface of the bulb. The difference between the two readings served as a measure of the actual current conveyed by the electrons from the heated spiral.

The earlier parts of the absorption curves in water for 64,000 and 96,000 volts are shown in fig. 2. The absorption is not exponential, but decreases steadily with increase of thickness of water. Knowing the initial saturation current through the air with no absorber, the total ionization current due to complete absorption of the radiation can be at once deduced by determining the area included between the curve and the two axes, assuming that $1 \mathrm{~cm}$. of water is equivalent in absorbing power to $8 \cdot 2$ metres of air at $15^{\circ} \mathrm{C}$.

Supposing that the $\mathrm{X}$ radiation from the tungsten anticathode is emitted equally in all directions, the fraction of the total radiation entering the ionization vessel was $8.6 \times 10^{-5}$.

The intensity of the radiation was found to be directly proportional to the current through the bulb. In the following table the total ionization current in air due to complete absorption of the whole radiation is expressed for each voltage in terms of 100 divisions of the current galvanometer which correspond to $2.92 \times 10^{-5} \mathrm{amp}$.

\begin{tabular}{|c|c|c|c|c|c|}
\hline Voltage. & $\begin{array}{l}\text { Current } i_{2} \text { due } \\
\text { Cathode Rays. }\end{array}$ & $\begin{array}{l}\text { Total Ionization } \\
\text { Current } i_{1} \text { for } \\
\text { Complete Absorp- } \\
\text { tion of the } \\
\text { Radiation. }\end{array}$ & $\mathbf{X}=i_{1} / i_{2 \cdot}$ & $\beta$. & $X / \beta^{+}$. \\
\hline 48,000 & $292 \times 10^{-5}$ amp. & $25 \times 10^{-5}$ amp. & $\cdot 86$ & $\cdot 406$ & 32 \\
\hline 64,000 & , & $4 \cdot 2$, & $1 \cdot 44$ & $\cdot 459$ & 32 \\
\hline 96,000 & ," & $8 \cdot 8 \quad$. & 3.01 & $\cdot 540$ & 35 \\
\hline
\end{tabular}

Beatty (loc. eit.) concluded from his experiments that $\mathrm{X}=.58 \mathrm{~A} \beta^{4}$, where $\mathrm{A}$ is the atomic weight of radiator and $\beta$ 
the velocity of the cathode rays as a fraction of the velocity of light. It is seen from the last column that $X / \beta^{4}$ is sensibly constant. Substituting the value of $A=184$ for tungsten, the values of $\mathrm{X}$ to be expected from this equation are $2 \cdot 9,4 \cdot 8,9 \cdot 1$ for $48,000,64,000$, and 96,000 volts respectively in place of $\cdot 86,1 \cdot 4,3 \cdot 0$ observed experimentally. The observed values are about one third of the values calculated on Beatty's relation.

\section{Correction for Absorption in Bulb.}

In our calculations, however, we have measured the total ionization produced outside the bulb, and have not corrected for the absorption of the rays by the wall of the bulb and by the air and other absorbers in the path of the rays. Special measurements showed that the wall of the bulb where the rays issued was $5 \mathrm{~mm}$. in thickness. The absorption in glass for equal thicknesses is about the same as for aluminium, and there will not be much error in taking the absorption of the rays before entering the ionization vessel as equivalent to $\cdot 6 \mathrm{~mm}$. of aluminium. Comparing the relative absorption of air and aluminium for soft radiations, $\bullet 6 \mathrm{~mm}$. of aluminium is equivalent to about $8 \mathrm{~mm}$. of water. Until experiments are made of the total radiation from tungsten under conditions that the absorption of radiation in escaping from the tube is a minimum, it is difficult to make more than a rough estimate of this correcting factor for absorption. From a consideration of the absorption curves in water, it seems probable that the correcting factor for the total ionization is at least 2 for 48,000 volts, and may be somewhat greater. It is to be expected that this factor would be somewhat less for the higher voltages. Making this correction, it is seen that the results for tungsten are in very fair agreement with Beatty's relation, even though it is extrapolated over a wide range of atomic weight and voltage.

\section{Energy of the $X$ Rays.}

Knowing the current due to complete absorption of the radiation, the energy of the radiation can at once be deduced if the average energy required to produce a pair of ions in air is known. The value of this important quantity can best be deduced from the total ionization current produced by the absorption of a single alpha particle of known energy. Geiger found that a single alpha particle from radium $C$ gave rise to $2.37 \times 10^{5}$ ions in air each of charge $4.65 \times 10^{-10}$ e.s. units, i. e. a quantity of electricity $3 \cdot 67 \times 10^{-15}$ e.m. units. 
On the latest data*, the initial energy of the alpha particle from radium $\mathrm{C}$ is $7 \cdot 66 \times 10^{14} e$, where $e$ is the charge on the ions in electromagnetic units. From this it can be deduced that the energy required to produce a pair of ions in air is equal to the energy acquired by the unit charge in moving freely through a potential difference of 33 volts. If $i_{1}$ is the total ionization current and $i_{2}$ the electronic current

$$
\text { efficiency }=\frac{\mathrm{X} \text {-ray energy }}{\text { cathode-ray energy }}=\frac{i_{1} v}{i_{2} \mathrm{~V}},
$$

where $v=33$ volts and $\mathrm{V}=$ the voltage applied to the tube.

\begin{tabular}{|c|c|c|c|c|}
\hline Voltage. & $\begin{array}{c}\text { Rittio, } \\
i_{1} / i_{2} .\end{array}$ & Efficiency. & $\beta^{2}$. & Efficiency $/ \beta^{2}$ \\
\hline 48,000 & .86 & $.59 \times 10^{-3}$ & $\cdot 165$ & 36 \\
$6 \pm, 000$ & 1.44 & .74, & .211 & 35 \\
96,000 & 301 & 1.04, & .292 & 3.6 \\
\hline
\end{tabular}

The efficiency deduced in the above table is for ordinary working conditions when no correction is made for absorption in the glass walls, \&c. Under these limitations, the efficiency is seen to be proportional to $\beta^{2}$. No doubt the closeness of the agreement is accidental, for the numbers would be changed if corrections were made for absorption of the radiation.

We have seen earlier that about half the energy of the radiation is probably absorbed in the bulb. We should consequently expect the efficiency under ideal conditions to be about $1 / 500$ for 96,000 volts, and $1 / 800$ for 48,000 volts. It is of interest to note that Wien (loc. cit.) found an efficiency of $1.09 \times 10^{-3}$ for a platinum anticathode, using a bolometer method to measure the energy of the $X$ rays for a potential of 58,700 volts supplied by an induction-coil. Since the average potential of the discharge due to an induction-coil is less than the maximum, it is to be expected that the efficiency of the coil would be somewhat higher than for an equal steady voltage supplied by a machine.

Beatty (loc. cit.) found the efficiency to be given by

$$
\mathrm{E}=2.54 \times 10^{-4} \mathrm{~A} \beta^{2} \text {. }
$$

The value of the numerical factor involves the average energy required to produce a pair of ions. This was deduced by a very indirect method by a combination of distinct investigations by Glasson and Whiddington. From the data

* Rutherford and Robinson, Phil. Mag. xxviii. p. 551 (1914). 
given by Beatty, it can be calculated that the energy assumed to produce a pair of ions in methyl iodide corresponds to 110 volts. This is undoubtedly more than three times too large, and the value of $\mathrm{E}=7 \cdot 6 \times 10^{-5} \mathrm{~A} \beta^{2}$ is nearer the truth, assuming the correctness of the other data involved. The formula gives an efficiency for 96,000 volts of $4.1 \times 10^{-3}$, which is about twice as high as that to be expected from our experiments with a Coolidge tube after the probable correction for absorption has been made*.

In these calculations no correction has been made for reflexion or scattering of cathode rays by the tungsten. No doubt the correction for this varies with the speed of the electrons, and must be considerable for very high voltages. In the absence of any definite data on this question, it seems desirable, however, to give the efficiency of the conversion of cathode rays into $X$ rays under actual working conditions.

The relations given by Beatty only apply to the "general" or "independent" radiation from an X-ray tube. As pointed out by Beatty, the efficiency rises rapidly when a characteristic radiation is strongly excited. The low percentage value obtained for the efficiency of a Coolidge tube for high voltages is thus an indication that the radiation is mainly of the "independent" type, and that the " $K$ " characteristic radiation is not so strongly excited as in the case of metals of lower atomic weight. This is borne out by the difficulty of detecting the presence of the " $K$ " characteristic of tungsten by absorption experiments, or by reflexion from crystals. It is only in the case of radioactive substances that the characteristic radiations of high frequency are strongly excited. No doubt this is due to the ideal conditions of excitation in this case, for the exciting electrons all come from the nucleus of the atom.

In the preceding paper we have shown that the voltage required to excite the most penetrating rays in tungsten is about twice that to be expected on the quantum theory, indicating that about half of the energy of the exciting electron can be transformed into radiation. From the low value of the efficiency at high voltages, viz. about $1 / 500$, it is clear that, on the average, 1 electron only in 200 is efficient in producing radiation.

University of Manchester, July 1915.

* Dr. Beatty has drawn my attention to the recent measurements of Barkla (Phil. Mag. xxv. p. 838, 1913), in which he finds that the total ionization in methyl iodide for cathode rays is 1.48 times that in air. Using the amended data, Beatty's relation becomes $\mathrm{E}=\cdot 51 \times 10^{-4} \mathrm{~A} \beta^{2}$, which is in fair accord with our measurements. 